\title{
Effectiveness of a Pilot Community Physical Activity and Nutrition Intervention in American Samoa
}

\author{
Salei'a Afele-Fa'amuli ${ }^{1}$, Whitney Katirai ${ }^{2}$, and Mark Dignan ${ }^{2}$ \\ ${ }^{1}$ United States Department of Agriculture, \\ Cooperative State Research Education and Extension Service \\ ${ }^{2}$ University of Kentucky Prevention Research Center, \\ Department of Internal Medicine
}

\begin{abstract}
Background: The addition of Western foods to the Samoan diet has greatly affected the health of the American Samoan people. The purpose of this study was to test the effectiveness of culturally tailored exercise and nutrition interventions for adults living in Tutuila, American Samoa.

Method: Villages in the eastern, central, and western parts of the island of Tutuila were recruited to participate in this study. Villages were randomly assigned to one of three culturally tailored interventions: 46 individuals in one village participated in an exercise intervention, 27 individuals in another village participated in a nutrition-education intervention, and 22 individuals in a third village participated in a combined exercise and nutrition-education intervention. Participants' nutrition knowledge was measured at pre- and post-intervention stages through a questionnaire. Body Mass Index (BMI), height, and weight were assessed at baseline and again at weeks 4, 8, and 12. Differences in mean BMI over time by group, were assessed using repeated measures ANOVA with baseline BMI as a covariate. To test for differences in nutrition knowledge over time by group, pair-wise comparisons were used for the percent of correct answers at baseline and at week 12 .

Results: All three groups realized a significant decrease in BMI, from 1.35 in the nutrition only group to 2.27 in the exercise and nutrition group. The exercise and nutrition group also showed significant gains in ability to identify foods high in fiber and fat.

Implications: This study demonstrates that decreases in BMI and increases in nutritional knowledge can be obtained through a culturally-tailored intervention, especially one that combines nutrition education and exercise.
\end{abstract}

(C) 2009 Californian Journal of Health Promotion. All rights reserved.

Keywords: physical activity, American Samoa, knowledge, nutrition

\section{Introduction}

The Samoan Islands are located in the South Pacific Ocean, approximately halfway between Hawai $i$ and Australia. According to archaeological evidence, Samoan people are Polynesians who have migrated from the west (the East Indies, the Malay Peninsula, or the Philippines). The oldest known site of human occupation in Samoa dates back to about 1000 BC, with the first Europeans reaching Samoa in 1722. Over the years, many nations have claimed authority over the Samoan Islands; however, in 1900 the Berlin Treaty ceded the western Samoan Islands to Germany and the eastern Samoan Islands to the United States (US). While Samoa (formerly Western Samoa) became an independent nation in 1962 after being ruled by the political influences of Germany, Great Britain, and New Zealand, Eastern or American Samoa continues its ties with the US as an unincorporated territory. Hence, American Samoa continues to be under the administrative direction of the US 
Department of the Interior (Hubbell, Luce, \& McMullin, 2005). This study was conducted in the US Territory of American Samoa, which has a population of 57,291 (US Bureau of the Census, 2000). Samoans are the second largest Pacific Islander (PI) population group in the US after Hawaiians, comprising $22.5 \%$ of the total PI population.

Compared to non-Hispanic Whites, American Samoans tend to be younger, have a higher birth rate, have fewer years of formal education, and have lower family incomes (US Census, 2000). The median age of American Samoans is 24.4 compared to the US median age of 35.4 (US Census, 2003). Less than $8 \%$ of all American Samoans have a Bachelor's degree, about half the rate of the US (Asian Pacific Islander American [APIA] Health Forum, 2000). Median household income is approximately the same for American Samoans when compared to the general population of the US $(\$ 40,058$ and $\$ 41,994$ respectively); however, American Samoan households are significantly larger than most US households (4.1 people vs. 2.6 people). The large family size has been shown to be related to the number of American Samoans $(20.2 \%)$ that live below the poverty level. The life expectancy for American Samoan men (71.0 years) and American Samoan women (74.9 years) is lower than white men (73.2 years) and white women (79.6 years) respectively (US Census, 2000).

\section{Dietary Changes in American Samoa}

Many 19th century visitors remarked on the good health of the Samoan population (MacPherson \& MacPherson, 1990). The wellbeing of the Samoans was attributed, at that time, to a hospitable environment; an excellent diet consisting of vegetables (or leafy greens), complex carbohydrates, and various types of seafood; limited opportunity for infectious disease exposure from outsiders; daily physical activity associated with walking, planting, farming, fishing, village recreational entertainment or competition; and a high standard of personal hygiene, including frequent bathing (Bindon, 1995). Samoans have appeared to have enjoyed a long stable period of good health prior to European exposure in the 19th century. The modernization of American Samoa and its engagement in the world economy in the second half of the 20th century brought about significant changes in diet, shifting Samoans from subsistence agriculture to wage labor and purchased foods. In 1995, Bindon found that the changing economic conditions also had a substantial impact on the traditional patterns of physical activity, as wage employment generally involves less physically demanding activities than those common prior to outside contact, resulting in high rates of obesity and obesityrelated diseases.

Substantial differences have been found when contrasting the dietary habits of American Samoans and those of the less modernized country of independent Samoa (APIA, 2000). American Samoans consumed significantly more energy as refined carbohydrates and fattysources of protein, but consumed less energy than independent Samoans from fat and saturated fat that are commonly found in traditional Samoan foods. American Samoans also take in higher amounts of cholesterol and sodium, possibly from eating more processed and packaged foods (APIA, 2000). American Samoan children are significantly heavier and taller than their counterparts in independent Samoa, with modernization being the main dietary influence (Bindon \& Zansky, 1986).

Taira et al. (2004) conducted a study in Hawai i of more than 44,000 insured individuals in order to identify common factors associated with obesity and found that Samoans had the highest rates of obesity. The prevalence of obesity for American Samoa was estimated at greater than $75 \%$ of adult women and $60 \%$ of adult men (Curtis, 2003). A majority of American Samoans are obese by age 30, and significant adult obesity has been shown to begin earlier in life among Samoans, such as American Samoans, who are the most exposed to modernization (McGarvey, 1991).

\section{Factors Contributing to Obesity in American Samoa}

Rapid westernization in the Pacific region after WWII led to many dietary and lifestyle changes, such as decreased physical activity and changes 
in dietary intake (Galanis, McGarvey, Quested, Sio, \& Afele-Fa'amuli, 1999). Along with westernization, significant changes in the traditional Samoan diet have taken place. An increase in the variety of refined foods and the use of purchased foods such as white sugar, white bread, un-enriched rice, canned fish, and fatty meats has decreased reliance upon traditional Samoan dietary items such as breadfruit, banana, taro, fish, seafood, and coconut (Bindon, 1983). The rapid changes in diet and physical activity caused by modernization, in combination with genetic factors, have played a major role in the significant increase in obesity within American Samoa.

Along with the prevalence of obesity in American Samoa, the rate of weight gain in Samoan populations is faster than that observed in non-Polynesian populations (Hodge, Dowse, Zimmet, \& Collins, 1995; Bell, Swinburn, Amosa, \& Scragg, 2001). Therefore, weight maintenance and slight decreases in BMI are very important.

Environment, diet, and exercise are not the only contributing factors to the extreme adiposity within the American Samoan population. The combination of Neel's (1962) concept of a thrifty-genotype concerning efficient metabolisms with Pacific archaeology and ethnohistory has led many scientists and academics to posit that adaptive evolution contributes to the high obesity rates of American Samoans. Samoans that lead a more traditional lifestyle have lower rates of overweight and obesity; therefore, McGarvey posits that the prevalence of obesity in Samoa is not simply an ethnic-group genetic trait for obesity, but that it is the result of a complex interaction between genetic susceptibilities and contemporary environments mediated by individual dietary and physical-activity patterns. As a result of modernization-related dietary diversity and decreased physical activity, what used to be a genetic adaptive response to famine has led to the large population of obese Samoans (Taira, Gronley, \& Chung, 2004). A similar thriftygenotype scenario has been suggested for obesity, hyperinsulemia, and type 2 (formerly non-insulin-dependent) diabetes mellitus in the Pima Indians of North America (Neel, 1962).

Thus, in the American Samoan population where a majority of the population is obese, preventing further weight gain at a community level may substantially lower the risk of cardiovascular disease (CVD), diabetes, and other serious obesity-related diseases.

The interventions of diet and exercise were chosen for this study because studies have demonstrated the effectiveness of regular physical activity and healthy eating in the prevention of obesity and obesity-related chronic diseases such as CVD, diabetes, cancer, hypertension, osteoporosis, and even depression (U.S. Department of Health and Human Services, 2005; Nehrlich, Nicol, \& Bredin, 2006; Booth \& Lees, 2007; Thompson, 2006; Lippi, Salvagno, \& Guidi, 2005). Numerous studies confirm that the combination of regular physical activity and balanced nutrition lead to better overall health (U.S. Department of Health and Human Services, 2005; Nehrlich, Nicol, \& Bredin, 2006; Booth \& Lees, 2007; Thompson, 2006; Lippi, Salvagno, \& Guidi, 2005).

\section{Cultural Targeting}

Research has also determined that in order for an intervention to achieve its anticipated results, it has to embrace and respect the local culture. Place- or community-based health promotion interventions that are locally or culturally appropriate are more successful when implemented in developed countries or in underdeveloped island countries like American Samoa. Kreuter, Lukwago, Bucholtz, Clark, and Sanders-Thompson (2003) have categorized the strategies used to make health promotion programs and materials more culturally appropriate, including evidential, linguistic, constituent-involving, and sociocultural strategies. Further, Pasick, D’Onfrio, and OteroSabogal (1996) have suggested that cultural targeting is a term which applies to a population for which a culturally appropriate intervention is developed. Kreuter et al. (2003) define cultural targeting as a "single intervention approach for a defined population that takes into account characteristics shared by the subgroups' 
members." This study targets Samoans from American Samoa who are members of a culture with a high incidence of obesity and overweight and with limited health education and knowledge regarding diet and health implications. To address the serious problem of endemic obesity in American Samoa a culturally appropriate intervention was developed. The purpose of this study was to test the effectiveness of the intervention, an exercise and nutrition program for adults living in American Samoa.

\section{Methods}

\section{Participants}

In total, 63 women and 32 men participated in this study. The mean age of female participants was 42 , and the mean age for male participants was 32. All participants were of Samoan ethnicity and nationality.

\section{Recruitment and Random Assignment}

This study was conducted on the island of Tutuila, the center of commerce and the main island of the five islands that comprise American Samoa. Three villages were recruited, one in the eastern, one in the central, and one in the western part of the island. Villages were randomly assigned to one of three culturally tailored interventions: 46 individuals (16 women, 30 men) in one village participated in an exercise intervention, 27 individuals ( 25 women, 2 men) in another village participated in a nutrition-education intervention, and 22 individuals (22 women) in a third village participated in a combined exercise and nutrition-education intervention. It is very unlikely that participants had any contact with each other, therefore avoiding contamination.

Prior to entering villages in American Samoa to introduce programs such as this study, official request for village entry must be requested of the Office of Samoan Affairs (OSA) of the American Samoa Government. OSA links government to village-based traditional leadership through the village mayor. Selected by the village council of chiefs, a village mayor is the official representative of each village to the government. Village mayors are an important source of community leadership that crosses religious, social, and economic boundaries.

Approval and cooperation of OSA were granted after the formal presentation of the study to the village mayors. The researcher met with some church ministers of the participating villages and presented a summary of the study's procedures and purpose. This study involved two to four different churches in each village. The researcher met with one or two church ministers from the different denominations in each village. The village mayors and church ministers offered their support and approval for the study and subsequently made a public announcement informing all village residents about the study and offering their endorsement. Recruitment of the study participants occurred mostly by word of mouth as initiated by the village mayors and continued by the elder study participants. There was no attrition of participants in this study. This low rate of attrition can be attributed to the type of culturally-appropriate intervention that allowed the participants to socialize and spend time with each other within their village. Many of the meetings, held in their own villages, turned into social events which afforded the participants a high level of comfort.

\section{Interventions}

The exercise participants attended a low-impact aerobic exercise program for 12-weeks, three times weekly, for 45-minutes to one hour. The low-impact exercise program was specifically created for this population by integrating the movements of traditional daily chores such as picking breadfruit, climbing trees, weeding, or cultural dances. The exercise curriculum was designed by the researcher with nearly 20 years of aerobic instruction (low-impact exercise and dancing) and nutrition education (formal and informal) experience through the American Samoa Community College (ASCC), Land Grant Program. Her classroom work extended into evening exercise and nutrition/health classes for the community. The high demand for outreach non-formal activities evolved into island-wide televised exercise and cooking shows and the initiation and recognition of the 
National Nutrition Month of March jointly by ASCC and the Department of Education.

Nutrition-education participants engaged in group lessons and discussions with a focus on increasing daily consumption of locally grown fruits and vegetables, high-fiber foods and reducing overall fat intake from store-bought fatty meats. Nutrition-education lessons were selected from the USDA Expanded Food \& Nutrition Education Program (EFNEP) curriculum, American Samoa Community College (ASCC), Land Grant Program. Prior to pioneering EFNEP in American Samoa when ASCC became a land grant institution in 1981, the researcher worked as an EFNEP program aide among Samoans in Hawai'i through the University of Hawai'i, Manoa Campus. Both in Hawai'i and in American Samoa, as expected, the researcher modified the nutrition curriculum applying traditional healthy food options without compromising nutritional content.

Strategies were employed in this study to make interventions more culturally appropriate, as categorized by Kreuter, Lukawago, Bucholtz, Clark, \& Sanders-Thompson (2003). One of the culturally appropriate strategies used in this study was the linguistic strategy that includes translating documents into the native language of the targeted population. In this study, the survey used to assess participants' nutrition knowledge was translated into Samoan in an attempt to be as culturally appropriate as possible. The translation of all documents was conducted by the researcher and verified by village chiefs out of respect for culture and tradition.

Second, evidential strategies strive to enhance the perceived relevance of a health issue by presenting evidence of its impact on a targeted population. In this study, the health information provided to all participants was presented with specific information as to its relevance to the Samoan population. Samoan past and current diet and population specific health issues were addressed in each education session, along with prevalence information on cancer and diabetes which are highly prevalent in American Samoa.
Constituent-involving strategies are an additional approach used to assure culturally appropriate educational interventions. This strategy includes utilizing indigenous staff members or persons familiar with the culture in substantive roles. The Principle Investigator of the study, a Samoan native who speaks fluent Samoan, conducted all of the interventions. The study also paid close attention to culturally appropriate administrative channels and worked within them to gain approval of and involvement from the entire community. This approach can provide important insights into the culture that are not easily observed but essential to a true cultural understanding of the participants.

Finally, this study uses socio-cultural strategies described as the deep structure of cultural sensitivity and recognize the group's cultural values, beliefs, and behaviors. These programs and materials reflect the inner aspects of the culture and reinforce the culture's values. This strategy was applied though the use of culturally appropriate exercises derived from motions and movements common to traditional Samoan daily activities such as planting, fruit picking, and traditional dances. In addition, the nutrition education conducted in this study used the traditional Samoan diet as its model of healthy eating, which increases the participants' knowledge about the health benefits of the traditional diet and further demonstrates the importance of traditional knowledge and culture.

\section{Consent}

All participants signed an informed consent in either English or Samoan. All participants were verbally advised that they should not participate if they had any medical conditions that could be affected by their participation. Throughout the study, a physician from the only hospital in American Samoa, LBJ Hospital, made occasional visits to advise participants during the intervention. This study received approval of the first established Human Subjects Protection Committee in American Samoa.

\section{Measures}

Height and weight measurements were taken by public health nurses of the American Samoa Department of Public Health using a portable weighted balance scale. Knowledge was 
assessed through a combination of selfadministered questionnaire, and verbally administered questionnaire as participants desired. The questionnaire was specifically developed for this project. It included elements of a standardized questionnaire, but was developed to be culturally appropriate for
American Samoa. The integration of verbal and written measurement techniques were used to assure comprehension of all participants. The questionnaire was handed out immediately after the intervention with the intent to offer reading assistance upon request as a group or individually, primarily in the Samoan language.

Examples of questions from the questionnaire included:

Here is a list of foods. Please tell me which ones you think are high in fat.

$\begin{array}{llll}\text { Fried chicken } & \text { Broiled fish } & \text { Panikeke } & \text { Corned Beef } \\ \text { White bread } & \text { Bananas } & \text { Cakes/Pies } & \text { French Fries } \\ \text { Soda } & \text { Cold cuts } & \text { Ice cream } & \text { Chips } \\ \text { Peanut butter } & \text { Doughnuts } & \text { Spam } & \text { Povi Masima } \\ \text { Mutton flaps } & \text { Butter } & \text { Jam/Jelly } & \text { Milk } \\ \text { Condensed milk } & \text { Syrup } & \text { Fruit cocktail } & \text { None } \\ \text { Saimin } \bullet & \text { Bongo• } & \text { Masi Saina } & \text { Don't Know }\end{array}$

Here is a list of foods. Please tell me which ones you think are high in fiber.

Taro $\diamond$

Banana

Breadfruit $\diamond$

Tapioca $\diamond$

Taamu $\diamond$

Corn Flakes
Hamburgers

Chicken

Lettuce

Cabbage

Baked Beans

Carrots
Rice

Apples

Oranges

Papaya

Citrus Fruits
- Panikeke - Samoan for pancake, either round or flat, made from white flour, water, cornstarch, and sugar to taste. Round pancakes are deepfried while flat are baked in oil (primarily vegetable oil or sometimes lard) or butter in a frying pan.

- Masi saina - home-made cracker made from white flour, eggs, water, butter or oil, coconut milk to taste, a bit of cornstarch. Masi saina is usually served during breakfast or in evenings as dessert with hot fresh Samoan cocoa.

-Taro, taamu, tapioca, and breadfruit - primary staples or starches like bread and dinner roll to westerners and rice to Asians. Breadfruit is a seasonal fruit that comes in different varieties. Taro, taamu (giant taro), and tapioca are root crops that grow all year round. Samoans prefer serving baked or boiled taro, taamu, tapioca, and breadfruit in lots of coconut milk.
- Bongo - imported from foreign countries, a popular treat children eat readily, similar to American unhealthy snacks like sugar-coated crackers, etc.

- Saimin - imported from Asian countries, noodles added to boiling water and stirred.

- Povi masima - salted beef, another favorite Samoan delicacy which is not inexpensive and usually served at special occasions, birthdays, parties, weddings, and Sunday feasts.

\section{Statistical Analysis}

Data were analyzed with SPSS version 13.0 (SPSS Inc, Chicago, Ill). Frequencies and descriptive statistics were used to describe the sample. Chi-square and tests were used, as appropriate, to assess univariate differences among participants in each of the three groups. The goal was to test mean Body Mass Index 
(BMI) changes over time by group. Repeated measures ANOVA, with baseline BMI as the covariate, was used to assess changes in mean BMI.

While the statistical power of the study is modest, the results of this small study may be meaningful. These results are among the first to be obtained from careful evaluation of a health promotion trial in this population. These results are informative to researchers and practitioners alike, but are particularly important to future research because they are the first results to be obtained from a health promotion trial focusing on obesity in this population, and the results will have great utility in planning more highpowered investigations in the future.

\section{Results}

All together, 95 individuals in three villages participated-46 in the exercise intervention, 27 in the nutrition intervention, and 22 in the combined exercise and nutrition intervention. The mean age of participants was 38.5 years $(\mathrm{SD}=12.2)$, and $66 \%$ were women. The average age of male participants was 32 and the average age of female participants was 42 . The average height was 5 feet 8 inches for male participants and 5 feet 4 inches for female participants. There was a $4.5 \%$ decrease in BMI for male participants between baseline and week 12 . For female participants, there was a $4.4 \%$ decrease in BMI between baseline and week 12 (Table 1).

Table 1. Changes in Average Weight and BMI, baseline and week 12

\begin{tabular}{|c|c|c|c|c|}
\hline & $\begin{array}{c}\text { Average baseline } \\
\text { weight (lbs) }\end{array}$ & $\begin{array}{c}\text { Average week- } \\
\text { 12 weight (lbs) }\end{array}$ & $\begin{array}{c}\text { Average } \\
\text { baseline BMI }\end{array}$ & $\begin{array}{c}\text { Average } \\
\text { week-12 BMI }\end{array}$ \\
\hline Male (n= 32) & 249.1 & 237.9 & 35.7 & 34.1 \\
\hline Female (n= 63) & 218.6 & 209.0 & 36.5 & 34.9 \\
\hline Total (n= 95) & 228.9 & 218.7 & 36.2 & 34.6 \\
\hline
\end{tabular}

Nutrition knowledge was measured at pre- and post-intervention stages (Table 2). After the 12week intervention was conducted, almost twice as many participants were able to identify correctly $\leq 50 \%$ of the high-fat foods listed. The exercise-and-nutrition group showed the greatest change in knowledge over time. At baseline, two (9\%) participants were able to identify correctly $\leq 50 \%$ of foods that are high in fiber. However, after the intervention, 17 (77.2\%) participants were able to identify correctly $\leq 50 \%$ of foods that are high in fiber, an increase of $68.2 \%$.

As reported previously, height and weight were assessed at baseline and again at weeks 4, 8, and 12. Differences between mean BMI values were tested over the period from baseline through week 12 by group. The mean BMI for each of the three groups were very different; therefore, ANOVA was used to control for baseline BMI in the analysis. Overall, the study groups had a total decrease in mean BMI of 1.61 (Table 2). Between weeks 4 and 8, there were no significant decreases in any study group. Between weeks 8 and 12, the exercise-andnutrition and nutrition-only groups showed significant decreases in BMI. For the period from baseline to week 12, significant decreases in BMI were found for each study group. To test for differences in BMI by study group, a repeated measures analysis of variance was used. Results from the analysis showed no significant difference in BMI among the study groups over the period from baseline to week 12 $(\mathrm{p}=.10)$. 
Table 2. Changes in Nutrition Knowledge Pre and Post Intervention, by study group

\begin{tabular}{|c|c|c|c|c|c|}
\hline Knowledge & & $\begin{array}{c}\text { Exercise } \\
(\mathrm{n}=46)\end{array}$ & $\begin{array}{c}\text { Nutrition } \\
(\mathrm{n}=27)\end{array}$ & $\begin{array}{c}\text { Ex + Nutr } \\
(\mathrm{n}=22)\end{array}$ & $\begin{array}{c}\text { Total } \\
(\mathrm{N}=95)\end{array}$ \\
\hline $\begin{array}{c}\text { Foods high in fiber } \\
\leq 50 \% \text { of correct answers }\end{array}$ & Pre & $\begin{array}{c}5 \\
(10.9 \%)\end{array}$ & $\begin{array}{c}2 \\
(7.4 \%)\end{array}$ & $\begin{array}{c}2 \\
(9 \%)\end{array}$ & $\begin{array}{c}9 \\
(9.6 \%)\end{array}$ \\
\hline $\begin{array}{c}\text { Foods high in fiber } \\
\leq 50 \% \text { of correct answers }\end{array}$ & Post & $\begin{array}{c}8 \\
(17.4 \%)\end{array}$ & $\begin{array}{c}3 \\
(11.1 \%)\end{array}$ & $\begin{array}{c}17 \\
(77.2 \%)\end{array}$ & $\begin{array}{c}28 \\
(29.5 \%)\end{array}$ \\
\hline $\begin{array}{c}\text { Foods high in fat } \\
\leq 50 \% \text { of correct answers }\end{array}$ & Pre & $\begin{array}{c}14 \\
(30.4 \%)\end{array}$ & $\begin{array}{c}8 \\
(29.6 \%)\end{array}$ & $\begin{array}{c}2 \\
(9 \%)\end{array}$ & $\begin{array}{c}24 \\
(25.4 \%)\end{array}$ \\
\hline $\begin{array}{c}\text { Foods high in fat } \\
\leq 50 \% \text { of correct answers }\end{array}$ & Post & $\begin{array}{c}14 \\
(30.4 \%)\end{array}$ & $\begin{array}{c}14 \\
(59.4 \%)\end{array}$ & $\begin{array}{c}22 \\
(99.7 \%)\end{array}$ & $\begin{array}{c}50 \\
(54.9 \%)\end{array}$ \\
\hline
\end{tabular}

\section{Discussion}

Rapid changes in diet and physical activity caused by modernization, in combination with genetic factors, continue to play a significant role in the high levels of obesity in American Samoa. The rapid rate of weight gain reported for this population places further importance on weight maintenance and minimal decreases in BMI. Research has shown that place- or community-based culturally appropriate health promotion interventions achieve greater success when implemented in developing countries such as American Samoa.

Results show that participants in the combined exercise-and-nutrition intervention group had the largest decrease in mean BMI and greatest increase in nutrition knowledge from baseline to week 12 . These results suggest that a combined intervention of exercise and nutrition was the most successful approach to decreasing mean BMI and increasing knowledge.

Numerous studies on the health benefits of physical activity and/or nutrition in preventing obesity and obesity-related diseases have shown similar results to those of this study (US Department of Health and Human Services, 2005; Nehrlich, Nicol, \& Bredin, 2006; Booth \& Lees, 2007; Thompson, 2006; Lippi, Salvagno, $\&$ Guidi, 2005). Previous studies concluded that physical activity and healthy eating are effective in reducing obesity and obesity-related diseases. Furthermore, these studies verify and recognize the significance of implementing culturally- appropriate interventions for ownership and adoption of health-enhancing programs in the community (Green \& Kreuter, 2000; Eriksen, 2005; National Cancer Institute, 2005; Brownson, Haire-Joshu, \& Luke, 2006; Hassel, 2006; Garrido, Auger, Rendon, \& Hassell, 2005; Afele-Fa'amuli, 2007; Staten, Scheu, Bronson, Pena \& Elenes, 2005; Aitaoto, Braun, Ka'ohimanu, \& So'a, 2007).

This study showed that weight loss was a result of the combination of culturally tailored lowimpact aerobics and the nutrition education program. All three groups demonstrated an overall decrease in mean BMI and an increase in ability to identify high-fat and high-fiber foods. At the conclusion of the study, formal speeches of appreciation were given according to the Samoan cultural tradition and in the Samoan language. The participants expressed that the program "opened their eyes to benefits of engaging in ordinary physical activities without cost such as walking on the beach or swimming in the ocean right in our own front yard, planting, digging and pulling weeds at the plantation, traditional dancing, and cooking."

It is important to view the results of this study within the Samoan cultural context of nutrition and physical activity. The results from this study should be interpreted in light of several limitations. First, participation was limited to adults, and the total sample size was relatively small. Findings from a larger number of participants encompassing a broader age range would strengthen the conclusions. The limited 
sample size and high proportion of female participants cause probable gender factor differences that remain unobserved. Due to the broad age dispersion among participants, age factor differences remain unobserved. Second, recruitment of participants was limited to a convenience sample and was not populationbased. Because the villages that were conveniently selected for participation were in different parts (eastern, central, and western) of the island of Tutuila, it is very unlikely that participants had contact with each other, therefore, avoiding contamination. Finally, health history data on the participants were not available.

\section{Implications for Research and Practice}

These findings are salient for nutrition educators and other health professionals working with obese adults, but specifically for those who work with the Samoan-American population. One of the implications for practice is the importance and relevance of culturally appropriate interventions and study procedures. It is imperative to conduct culturally-appropriate programs for effectiveness and ownership. Participation and reduction of BMI in all three groups may be attributed in some part, to the intense cultural respect for the researcher who is Samoan and speaks fluent Samoan. Participants attempted their best performance to demonstrate their appreciation and respect for the "teacher" who travelled quite a distance to teach exercise and nutrition.

One way this study could have a sustained impact would be to partner with the Department of Public Health. The Department of Public
Health is already visible through village-based district Public Health Centers. The Centers are an existing resource that should be included in a sustained intervention, and village residents should take leadership in developing programs that integrate physical activity and nutrition education for their communities. This initiative would strengthen outreach, cultural inclusiveness and probable ownership of the program by the community due to their involvement in the planning and implementation of the programs. The culturally-appropriate, systemic, and multi-disciplinary approaches to health interventions have shown consistent success in minimizing health disparities in many studies (Green \& Kreuter, 2000; Eriksen, 2005; National Cancer Institute, 2005; Brownson, Haire-Joshu, \& Luke, 2006; Hassel, 2006; Garrido, Auger, Rendon, \& Hassell, 2005; Afele-Faamuli, 2007; Staten, Scheu, Bronson, Pena \& Elenes, 2005; Aitaoto, Braun, Ka'ohimanu, \& So'a, 2007).

These results also bring into sharp relief the concept of cultural sensitivity. Changing health behaviors in a population that may have come to accept obesity as "normal" is likely to require great insight into the needs, interests, and values of the culture. Future research should begin with careful assessment of the views of obesity commonly held by the population and their views of efforts to introduce weight control and/or exercise programs.

Acknowledgement: The authors thank Drs. Kathryn Braun and Sora Park Tanjasiri for their contribution to development of this manuscript.

\section{References}

Afele-Fa' amuli, S. (2007). Life, culture, and care of Polynesians: Serving food is a big ritual. In Pati and Schwartz-Herion (Eds.), Sustainable development: Issues and perspectives (pp. 389397). New Dehli: D.K. Printworld.

Aitaoto, N., Braun, K.L., Ka'ohimanu, L.D., \& So'a, T.L. (2007). Cultural considerations in developing church-based programs to reduce cancer health disparities among Samoans. Ethnicity and Health, 12, 381-400.

Asian and Pacific Islander American Health Forum. (August 2006). Samoans in the United States. Retreived October 22, 2008, from http://www.apiahf.org/resources/pdf/Samoans_in_the_ United_States.pdf

Bell, A.C., Swinburn, B.A., Amosa, H., \& Scragg, R.K. (2001). A nutrition and exercise 
intervention program for controlling weight in Samoan communities in New Zealand. International Journal of Obesity, 25, 920-927.

Bindon, J.R., (1983). Breadfruit, banana, beef, and beer: Modernization of the Samoan diet. Ecology of Food and Nutrition, 12, 49-60.

Bindon, J.R., \& Zansky, S.M. (1986). Growth patterns of height and weight among three groups of Samoan preadolescents. Annual Human Biology, 13, 171-178.

Bindon, J.R. (1995). Polynesian responses to modernization: Overweight and obesity in the South Pacific. In deGarine and Pollock (Eds.), Social aspects of obesity. (pp. 227-251).London: Gordon and Breach.

Booth, F.W., \& Lees, S.J. (2007). Fundamental questions about genes, inactivity, and chronic diseases. Physiologic Genomics, 28, 146-157.

Brownson, R.C., Haire-Joshu, D., \& Luke, D.A. (2006). Shaping the context of health: A review of environmental and policy approaches in the prevention of chronic disease. Annual Review of Public Health, 27, 341-370.

Curtis, M. (2003). The obesity epidemic in the Pacific Islands. Journal of Development and Social Transformation, 1, 37-42.

Eriksen, M. (2005). Lessons learned from public health efforts and their relevance to preventing childhood obesity. In Koplan, J.P., Liverman, C.T., \& Kraak, V.A. (Eds.), Preventing Childhood Obesity: Health in the Balance (pp. 343-375). Washington, DC: National Academy of Sciences.

Galanis, D.J., McGarvey, S.T., Quested, C., Sio, B., \& Afele-Fa'amuli, S. (1999). Dietary intake of modernizing Samoans: Implications for risk of cardiovascular disease. Journal of American Dietetic Association, 99, 184-190.

Garrido, D.J., Auger, S., Rendon, S., \& Hassel, C. (2005). Nutrition through another lens: Indigenous knowledge in nutrition education. Journal of Nutrition Education and Behavior, 37 (Suppl 1), $35 \mathrm{~s}$.

Green, L.W., \& Kreuter, M. (2000). Health promotion planning: An educational and ecological approach. New York, NY: McGraw-Hill.

Hassel, C. (2006). Woodlands wisdom: A nutrition program interfacing indigenous and biomedical epistemologies. Journal of Nutrition Education and Behavior, 38, 114-120.

Hodge, A.M., Dowse, G.K., Zimmet, P.Z., \& Collins, V.R. (1995). Prevalence and secular trends in obesity in Pacific and Indian Ocean island populations. Obesity Research, 3, 77s-85s.

Hubbell, F.A., Luce, P.H., \& McMullin, J.M. (2005). Exploring beliefs about cancer among American Samoans: Focus group findings. Cancer Detection and Prevention, 29, 109-115.

Kreuter, M.W., Lukawago, S.N., Bucholtz, D.C., Clark, E.M., \& Sanders-Thompson, V. (2003). Achieving cultural appropriateness in health promotion programs: Targeted and tailored approaches. Health Education and Behavior, 30, 133-146.

Lippi, G., Salvagno, G.L., \& Guidi, G.C. (2005). Other advantages to aerobic exercise [letter]. Canadian Medical Association Journal, 173, 1066.

MacPherson, C., \& MacPherson, L. (1990). Samoan medical belief \& practice. Aukland: Aukland University Press.

McGarvey, S.T. (1991). Obesity in Samoans and a perspective on its etiology in Polynesians. American Journal of Clinical Nutrition, 53, 1586s-1594s.

National Cancer Institute. (2005). ASSIST: Shaping the future to tobacco prevention and control. (Publication No. 05-5645). Bethesda, MD: U.S. Department of Health and Human Services, National Institutes of Health, National Cancer Institute.

Neel, J.V. (1962). Diabetes mellitus: A thrifty genotype rendered detrimental by "progress"? American Journal of Human Genetics, 14, 353-62.

Nehrlich, H.H., Nicol, C.W., \& Bredin, S.B. (2006). Health benefits of physical activity: The evidence. Canadian Medical Association Journal, 175, 773-777. 
Pasick, R.J., D’Onfrio, C.N., \& Otero-Sabogal, R. (1996). Similarities and differences across cultures: Questions to inform a third generation for health promotion research. Health Education Quarterly, 23, 142s-161s.

Staten, L.K., Scheu. L.L., Bronson, D., Peña, V., \& Elenes, J. (2005). Pasos Adelante: The effectiveness of a community-based chronic disease prevention program. Preventing Chronic Disease, 2, 1-11.

Taira, D., Gronley, K., \& Chung, R. (2004). Patient characteristics, health status, and health-related behaviors associated with obesity. Hawaii Medical Journal, 63, 150-154.

Thompson, H.J. (2006). Pre-Clinical investigations of physical activity and cancer: A brief review and analysis. Carcinogenesis, 27, 1946-1949.

U.S. Department of Health and Human Services and U.S. Department of Agriculture. (2005). U.S. dietary and physical activity guidelines for Americans 2005. 6th Ed. (DHHS Publication No. 001-00004719-1). Washington, DC: US Government Printing Office.

U.S. Bureau of the Census. (2000). We the people: Pacific Islanders in the United States. Washington, DC: U.S. Bureau of the Census.

U.S. Bureau of the Census. (2003). The island areas. Washington, DC: U.S. Bureau of the Census.

Author Information

Salei'a Afele-Fa'amuli, $\mathrm{PhD}, \mathrm{MPH}^{*}$

United States Department of Agriculture

Cooperative State Research Education and Extension

Service (CSREES)

1400 Independence Ave., SW. Stop 2250

Washington, D.C. 20250-2250

Telephone: (202) 720 - 0384

Facsimile: (202) 720 - 4924

Email: sfaamuli@csrees.usda.gov

Whitney Katirai, MPH

University of Kentucky, Prevention Research Center

Department of Internal Medicine

Mark Dignan, $\mathrm{PhD}, \mathrm{MPH}$

University of Kentucky, Prevention Research Center

Department of Internal Medicine

* corresponding author 


\section{Appendix A}

\section{Figure 1}

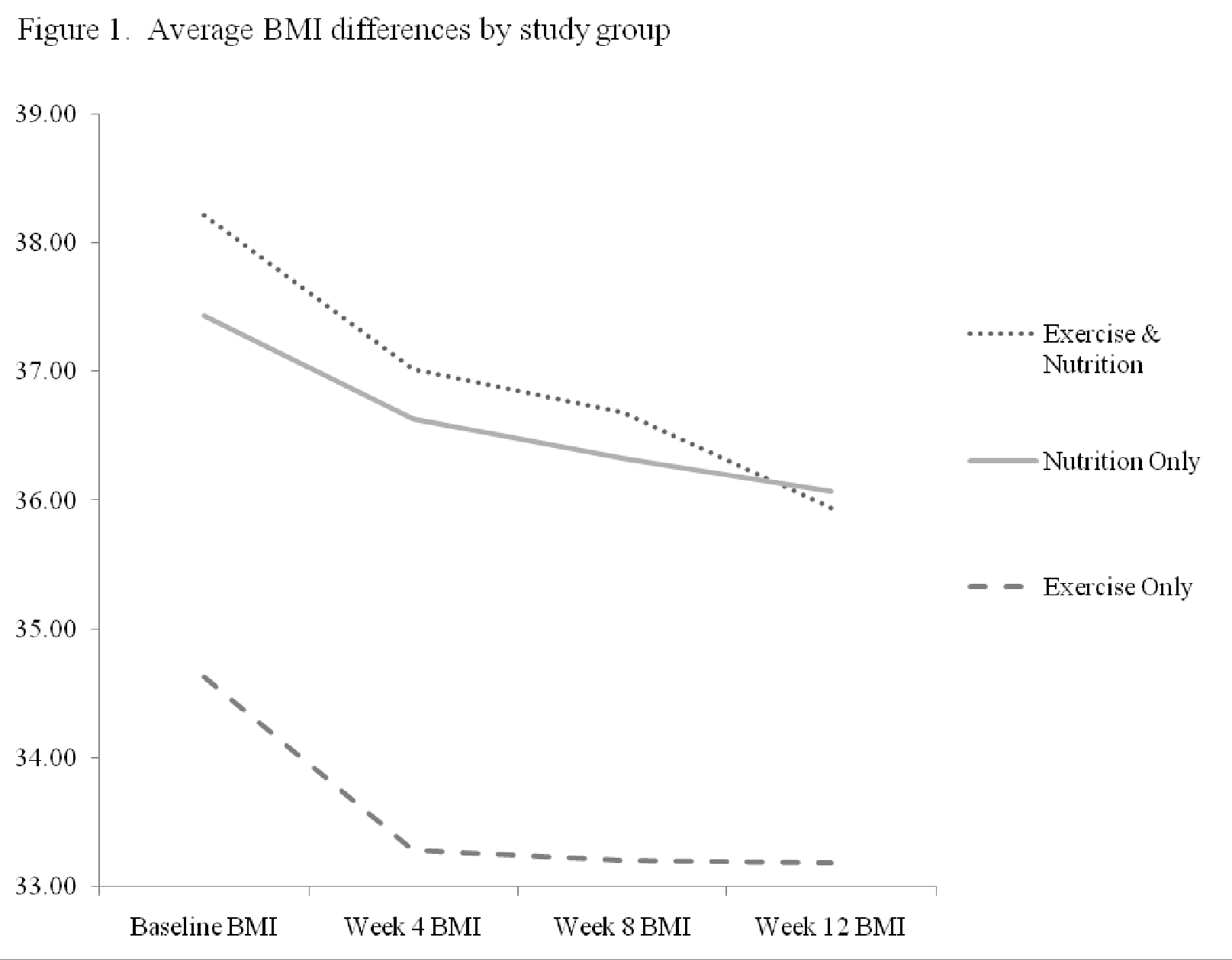

